\title{
Editorial: The Effects of Climate Change and Environmental Factors on Exercising Children and Youth
}

\author{
Shawnda A. Morrison ${ }^{1 *}$, Julien D. Périard ${ }^{2}$, Patrick De Boever ${ }^{3,4}$ and Hein A. M. Daanen ${ }^{5}$ \\ ${ }^{1}$ Center for Climate Change and Active Children, Faculty of Sport, University of Ljubljana, Ljubljana, Slovenia, ${ }^{2}$ Faculty of \\ Health, Research Institute for Sport and Exercise, University of Canberra, Canberra, ACT, Australia, ${ }^{3}$ Department of Biology, \\ University of Antwerp, Antwerp, Belgium, ${ }^{4}$ Centre for Environmental Sciences, Hasselt University, Diepenbeek, Belgium, \\ ${ }^{5}$ Department of Human Movement Sciences, Faculty of Behavioural and Movement Sciences, Amsterdam Movement \\ Sciences, Vrije Universiteit Amsterdam, Amsterdam, Netherlands
}

Keywords: global warming, environmental epidemiology, hyperthermia, active play, COVID-19, hypoxia, pediatric health

\section{Editorial on the Research Topic}

\section{The Effects of Climate Change and Environmental Factors on Exercising Children and Youth}

\section{OPEN ACCESS}

Edited by:

Franck Brocherie,

Institut National du sport, de l'expertise et de la Performance

(INSEP), France

Reviewed by:

Sean R. Notley,

University of Ottawa, Canada

${ }^{*}$ Correspondence:

Shawnda A. Morrison shawnda.morrison@fsp.uni-lj.si

Specialty section: This article was submitted to Elite Sports and Performance Enhancement,

a section of the journal Frontiers in Sports and Active Living

Received: 02 April 2021 Accepted: 10 May 2021 Published: 28 May 2021

Citation: Morrison SA, Périard JD, De Boever P and Daanen HAM (2021) Editorial: The Effects of Climate Change and Environmental Factors on Exercising Children and Youth.

Front. Sports Act. Living 3:690171. doi: 10.3389/fspor.2021.690171
The effects of climate change will exert both indirect (e.g., ecosystem disruption, air pollution, and changing disease-vector patterns) and direct (e.g., droughts, floods, wildfires, temperature increases) impacts on human health (Figure 1), especially in vulnerable populations like children (Helldén et al., 2021). How these factors affect physical activity (PA) in children is less frequently investigated. Indeed, child health is not prioritized in policy-making to the level required to reduce harm (Pegram and Colon, 2019). A recent scoping review concluded that children will experience high morbidity and mortality burden in the coming years because of climate change (Helldén et al., 2021).

This Research Topic's goal was to collate investigations on how acute and chronic exposure(s) to environmental factors affect exercising children. Four papers were accepted on varied topics, including the influence of hypobaria on heart rate variability (Aebi et al.), outdoor PA trends in urban environments (Bao et al.), the effect of summer holidays on PA (Volmut et al.), and how to respond to pandemic self-isolation measures (Jurak et al.). In this editorial, three indirect effects of climate change and child health are explored, including (1) air quality and pressure, (2) urban design and active play, and (3) changing disease-vector patterns, and one direct effect, (4) high ambient temperatures.

\section{AIR QUALITY AND PRESSURE}

Burning fossil fuels cause complex atmospheric emissions and negatively affects air quality. Compared to adults, children have rapidly-developing respiratory and immunological systems and smaller peripheral airways, making them particularly vulnerable to air pollution. Early-life exposure to air pollutants increases the risk of childhood health problems and predisposes them to chronic disease in adulthood (Perera, 2017). Young children, and especially the poor, suffer from environmental injustice because of these effects (Mathiarasan and Hüls, 2021). Ventilation rates increase during exercise. When this occurs, the inhaled air pollution dose increases, penetrating deeper into lung tissues, yet studies investigating PA and air pollution interactions have focused mainly on adults (Tainio et al., 2021). The composition and pressure of air also affect gas exchange in humans; environmental hypoxia occurs when there is a decrease in inspired oxygen 
pressure, which affects cardiac autonomic function. In their work, Aebi et al. tested young flight pilots. The authors confirmed that hypobaric hypoxia increases minute ventilation, decreases oxygen saturation, and affects heart rate variability parameters more so than under normobaric hypoxic conditions.

\section{URBAN DESIGN AND ACTIVE PLAY}

Modern society, especially in higher socio-economic status countries, often struggles to balance the idea of keeping children healthy and active vs. protecting them from serious harm. Many adults consider cities unsafe for children to play unsupervised, especially regarding outdoor PA and active play. In this way, adults may hinder children's natural ability to develop and learn, especially in outdoor environments. In their paper (Bao et al.) found that when children's PA spaces were fenced in, or featured excessive artificial design, uniform equipment, or the area lacked consideration of children's needs, outdoor PA was lower than in areas incorporating natural elements like green space, water, and sandy features. Measuring spontaneous, active play in children is notoriously difficult; however, objective devices like accelerometers can help quantify PA. Interestingly (Volmut et al.) reported that kids' overall PA decreased by $\sim 18 \%$, and physical inactivity increased by $5.5 \%$ during summer holidays. Negative PA trends can be exacerbated as summers continue to warm, includng more extensive heatwaves. We should consider this evolution when kids have less access to structured, quality physical education minutes as they typically do during school time.

\section{CHANGING DISEASE VECTOR PATTERNS}

Climate change will significantly affect disease-carrying vector distribution such that weather patterns will affect transmission and survival of infectious pathogens (Ahdoot and Pacheco, 2015). Therefore, the extraordinary impact the COVID19 pandemic has had on human movement restrictions will probably not be a one-off situation. From the early days of the pandemic, researchers sounded the alarm on the negative impact of isolation, confinement, and physical (in)activity on all persons (Burtscher et al., 2020) and children in particular (Morrison et al., 2020). In their article (Jurak et al.) outline the grave costs these restrictive measures have had on children's physical fitness, noting that their research group has observed the most significant decrease in child fitness in the $>30$ year history since systematic fitness testing began in Slovenia. The researchers detail a novel SLOfit Barometer system as a tool to engage in public health surveillance for the public and policymakers, hoping that other countries will use this model to create their systems of advocating for child health.

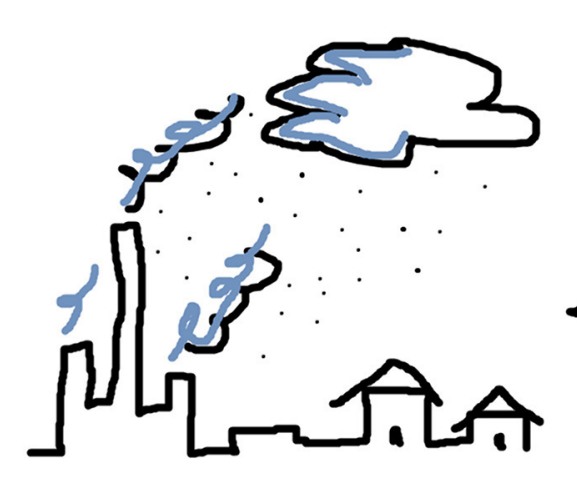

Direct Effects Temperature changes Precipitation changes Droughts and wildfires Floods

Indirect Effects Urban heat islands Air quality Active play environments

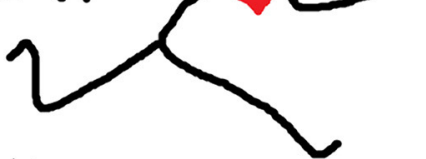

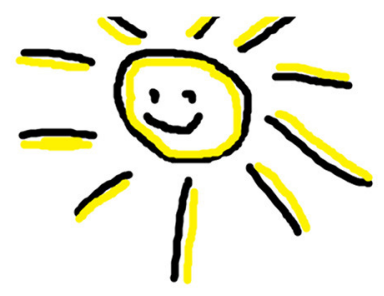
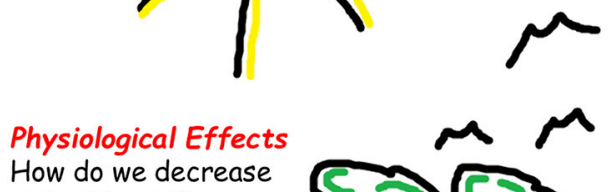

How do we decrease risk of heat illness, increase fitness \& build resiliency?

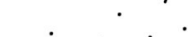

Indirect Effects Ecosystem destruction Changing vector patterns Aeroallergens

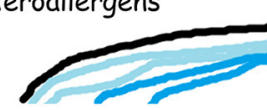

FIGURE 1 | Effects of climate change on the health of exercising children. Climate change will require human adaptation to its direct (e.g., temperature changes, floods) and indirect interconnected effects (e.g., air pollution, changing disease vector patterns), especially in children, who are considered a vulnerable population and have not been the focus of recent scientific research or policy making to this point, despite clear evidence that children require special focus to reduce health risk. The heading "Physiological effects" refers to both positive and negative adaptations to climate change, from exposure to environmental factors like air pollution and heat, to being aware of the ongoing changes in body constitution of children (e.g., increasingly overweight) as a result of increased sedentary behavior and physical inactivity, which may directly affect heat tolerance and resiliency. 


\section{HIGH AMBIENT TEMPERATURES}

Children play, and when they do so in the heat, they may be at health risk as body temperatures rise (McGarr et al., 2021). Conversely, exercise in the heat leads to physiological adaptation, reducing heat strain. Unfortunately, information on the risks:benefits of active heat strain in children is lacking. During hot summer periods, which will occur more frequently because of climate change, children may be challenged to maintain stable body core temperatures due to slight differences in heat loss mechanisms compared with adults (Smith, 2019; Notley et al., 2020). Behavioral thermoregulation is compromised in small children who depend on supervisory control. It was recently shown that caretakers in daycare centers cannot accurately assess the children's thermal status, unlike their own thermal state (Folkerts et al., 2020). This poses an additional risk of heat strain for small children. Over two

\section{REFERENCES}

Ahdoot, S., and Pacheco, S. (2015). Global climate change and children's health. Pediatrics 136, e1468-1484. doi: 10.1542/peds.2015-3233

Bar-Or, O., and Wilk, B. (1996). Water and electrolyte replenishment in the exercising child. Int. J. Sport Nutr. Exercise Metab. 6, 93-99. doi: $10.1123 /$ ijsn.6.2.93

Burtscher, J., Burtscher, M., and Millet, G. P. (2020). (Indoor) isolation, stress and physical inactivity: vicious circles accelerated by Covid-19? Scand. J. Med. Sci. Sports 30, 1544-1545. doi: 10.1111/sms.13706

Folkerts, M. A., Gerrett, N., Kingma, B. R. M., Zuurbier, M., and Daanen, H. A. M. (2020). Care provider assessment of thermal state of children in day-care centers. Build. Environ. 179:106915. doi: 10.1016/j.buildenv.2020.106915

Ghosh, R., Dubey, M. J., Chatterjee, S., and Dubey, S. (2020). Impact of COVID19 on children: special focus on the psychosocial aspect. Minerva Pediatrica 72, 226-235. doi: 10.23736/S0026-4946.20.05887-9

Helldén, D., Andersson, C., Nilsson, M., Ebi, K., Friberg, P., and Alfvén, T. (2021). Climate change and child health: a scoping review and an expanded conceptual framework. Lancet Public Health 5, e164-e175. doi: 10.1016/S2542-5196(20)30274-6

Mathiarasan, S., and Hüls, A. (2021). Impact of environmental injustice on children's health-interaction between air pollution and socioeconomic status. Int. J. Environ. Res. Public Health 18:795. doi: 10.3390/ijerph18020795

McGarr, G. W., Saci, S., King, K. E., Topshee, S., Richards, B. J., Gemae, M. R., et al. (2021). Heat strain in children during unstructured outdoor physical activity in a continental summer climate. Temperature 8, 80-89. doi: $10.1080 / 23328940.2020 .1801120$

Morris, N. B., Jay, O., Flouris, A. D., Casanueva, A., Gao, C., Foster, J., et al. (2020). Sustainable solutions to mitigate occupational heat strain - an umbrella review of physiological effects and global health perspectives. Environ. Health 19:95. doi: 10.1186/s12940-020-00641-7

Morrison, S. A., Jurak, G., and Starc, G. (2020). Responding to a global pandemic: republic of Slovenia on maintaining physical activity during decades ago, research on heat strain in children was more prevalent. For example, researchers observed that hydration status is considerably better-maintained when children drink flavored vs. unflavored water (Bar-Or and Wilk, 1996). This type of research, with practical impact, should be revived now that it appears children can be at greater thermal risk during everyday life. Climate change, bush fires threatening schoolchildren's health (Requia et al., 2021), and inactivity caused by COVID19 (Ghosh et al., 2020), each justify a need to increase research focused on exercising children, similar to the attention recently given to occupational heat strain (Morris et al., 2020).

\section{AUTHOR CONTRIBUTIONS}

All authors listed have made a substantial, direct and intellectual contribution to the work and approved it for final publication.

self-isolation. Scand. J. Med. Sci. Sports 30, 1546-1548. doi: 10.1111/sms. 13745

Notley, S. R., Akerman, A. P., Meade, R. D., McGarr, G. W., and Kenny, G. P. (2020). Exercise thermoregulation in prepubertal children: a brief methodological review. Med. Sci. Sports Exerc. 52, 2412-2422. doi: 10.1249/MSS.0000000000002391

Pegram, J., and Colon, C. (2019). Are Climate Change Policies Child-Sensitive?. [New York, NY: United Nations Children's Fund (UNICEF)].

Perera, F. P. (2017). Multiple threats to child health from fossil fuel combustion: impacts of air pollution and climate change. Environ. Health Perspect. 125, 141-148. doi: 10.1289/EHP299

Requia, W. J., Roig, H. L., and Schwartz, J. D. (2021). Schools exposure to air pollution sources in Brazil: a nationwide assessment of more than 180 thousand schools. Sci. Total Environ. 763:143027. doi: 10.1016/j.scitotenv.2020. 143027

Smith, C. J. (2019). Pediatric thermoregulation: considerations in the face of global climate change. Nutrients 11:2010. doi: 10.3390/nu11092010

Tainio, M., Jovanovic Andersen, Z., Nieuwenhuijsen, M., Hu, L., De Nazelle, A., An, R., et al. (2021). Air pollution, physical activity and health: A mapping review of the evidence. Environ. Int. 147:105954. doi: 10.1016/j.envint.2020.105954

Conflict of Interest: The authors declare that the research was conducted in the absence of any commercial or financial relationships that could be construed as a potential conflict of interest.

Copyright (c) 2021 Morrison, Périard, De Boever and Daanen. This is an open-access article distributed under the terms of the Creative Commons Attribution License (CC $B Y)$. The use, distribution or reproduction in other forums is permitted, provided the original author(s) and the copyright owner(s) are credited and that the original publication in this journal is cited, in accordance with accepted academic practice. No use, distribution or reproduction is permitted which does not comply with these terms. 